\title{
A FAMÍlIA NYMPHAEACEAE NO PANTANAL, MATO GROSSO E MATO GROSSO DO SUL, BRASIL ${ }^{1}$
}

\author{
Vali Joana Pott ${ }^{2}$
}

\section{Recebido em 7/1 1/1996. Aceito em 28/08/1998}

\begin{abstract}
RESUMO - (A família Nymphaeaceae no Pantanal, Mato Grosso e Mato Grosso do Sul, Brasil). As Nymphaeaceae possuem 50 espécies em 6 gêneros, dos quais dois ocorrem no Pantanal, Nymphaea (7 spp.) e Victoria (1). As espécies de Nymphaea encontradas são todas do subgênero Hydrocallis, neotropicais de floração noturna. As espécies encontradas no Pantanal são: Victoria amazonica (Poepp.) Sowerby. Nymphaea amazonum Mart. \& Zucc. subsp. amazonum. e subsp. pedersenii Wiersema, N. belophylla Trickett., N. gardneriana Planch., $N$. jamesoniana Planch., N. lingulata Wiersema., N. oxypetala Planch. e N. prolifera Wiersema. A espécie de mais ampla distribuição no Pantanal é $N$. amazonum. $N$. lingulata e $N$. belophylla são citadas pela primeira vez para o Pantanal. São apresentadas chave de identificação das espécies baseada em caracteres morfológicos. breve descrição. observações ecológicas, distribuição e ilustrações.
\end{abstract}

Palavras-chave - hidrófita, macrófita aquática, Nymphaeaceae

\begin{abstract}
The Nymphacaceae family in the Pantanal. Mato Grosso and Mato Grosso do Sul, Brazil). The Nymphaeaceae includes 50 species of 6 genera, of which two occur in the Pantanal wetland, Nymphaea (7 species) and Victoria (1). The surveyed species of Nymphaea all belong to the subgenus Hydrocallis, neotropical with nocturnal flowering. The species found in the Pantanal are Victoria amazonica (Poepp.) Sowerby, Nymphaea amazonum Mart. \& Zucc. subsp. amazonum and subsp. pedersenii Wiersema, N. belohylla Trickett, $N$. gardneriana Planch., N. jamesoniana Planch., N. lingulata Wiersema, N. oxypetala Planch. and $N$. prolifera Wiersema. The species with the widest distribution in the Pantanal is $N$. amazonum. $N$. lingulata and $N$. belophylla are cited for the first time for the Pantanal. A species identification key based on morphological characters, brief descriptions, ecological observations, distribution and illustrations are presented.
\end{abstract}

Key words - aquatic plant, aquatic macrophyte, Nymphaeaceae, waterlily, wetland

\section{Introdução}

Apenas Caspary (1878), Hoehne (1948) e Wiersema (1987) tratam sobre a taxonomia de certas espécies de Nymphaeaceae que ocorrem no Brasil. Gessner (1962) estudou a

I Auxilio $\mathrm{CNPq}$

2 Centro de Pesquisa Agropecuária do Pantanal CPAP, EMBRAPA. C. Postal 109, CEP 79320-900, Corumbá, MS, Brasil 
abertura das flores de Vitoria amazonica (Poepp.) Sowerby em relação à luz. Prance (1974) se refere a problemas taxonômicos de V. amazonica, V. regia Lindl. V. cruziana A. D. Orb.

Prance \& Arias (1975) e Prance \& Anderson (1976) tratam da biologia floral de $V$. amazonica, N. rudgeana G. Mey. e N. ampla (Salisb.) DC. Prance \& Schaller (1982) citam apenas $V$. amazonica e $N$. amazonum para o Pantanal.

O estudo e o manejo de áreas alagadas exigem a identificação correta das espécies (Wade 1987). Este trabalho foi realizado com o objetivo de atender a crescente necessidade de levantamentos florísticos regionais, a realização de relatórios de impacto ambiental, e ainda, a falta de chaves de identificação para o Pantanal sobre a família Nymphaeaceae e de material didático para atender aos alunos de Biologia da região.

\section{Material e métodos}

O Pantanal é uma planície sedimentar inundável, com $140.000 \mathrm{~km}^{2}$, entre as coordenadas $16^{\circ}$ a $22^{\circ} \mathrm{S}$ e $55^{\circ}$ a $58^{\circ} \mathrm{W}$. A precipitação média é de $1.100 \mathrm{~mm}$ ao ano (Cadavid-Garcia 1984).

O trabalho foi realizado através do cultivo das espécies e de coletas em todas as sub-regiões e ambientes como rios, cursos intermitentes (vazantes e corixos), brejos, baías (lagoas), caixas de empréstimo e campos alagados. O material botânico está depositado no Herbário CPAP do Centro de Pesquisa Agropecuária do Pantanal, EMBRAPA. Também foi examinado o material do Herbário COR do Centro Universitário de Corumbá, e do Herbário Central UFMT, da Universidade Federal de Mato Grosso em Cuiabá. Os dados de material examinado referente ao Herbário $(Z)$ de Zürich foram obtidos de Dubs (1998), quando havia duplicata no Herbário CPAP ou COR.

As Nymphaeaceae foram identificadas com base nos trabalhos de Wiersema (1984a; b; 1987) e Trickett (1971). As medidas das folhas e o número dos estames, quando entre parênteses, são de Wiersema (1987).

Figuras foram feitas à lupa estereoscópica com o auxílio de câmara clara.

\section{Resultados e discussão}

Dois gêneros de Nymphaeaceae ocorrem no Pantanal, Nymphaea (7 espécies) e Victoria (1 espécie). As espécies encontradas no Pantanal são Victoria amazonica (Poepp.) Sowerby, Nymphaea amazonum Mart. \& Zucc. subsp. amazonum e subsp. pedersenii Wiersema, $N$. belophylla Trickett, $N$. gardneriana Planch., $N$. jamesoniana Planch., $N$. lingulata Wiersema, $N$. oxypetala Planch. e $N$. prolifera Wiersema. As espécies $N$. lingulata e $N$. belophylla são citadas pela primeira vez para o Pantanal, esta última com apenas três coletas em Mato Grosso, na área de inundação do rio Paraguai, em Cáceres, e em Poconé e Santo Antônio do Leverger.

Descrição da família Nymphaeaceae - A família Nymphaeaceae possui seis gêneros, totalizando 50 espécies (Burkart et al. 1987), das quais 40 são do gênero Nymphaea (Cook 1990). Tem ampla distribuição nas regiões tropicais e temperadas de todo o mundo (Burkart et al. 1987); é constituída de plantas aquáticas de folhas flutuantes, às vezes submersas, longamente pecioladas e enraizadas no substrato; de bainha peltada, 
cordada ou sagitada; flores solitárias, pedunculadas; sépalas 4-6; pétalas e estames numerosos, de disposição espiralada; gineceu com 3 a muitos carpelos unidos, formando um ovário pluricarpelar, com prolongamentos chamados de apêndices carpelares ("estaminódios"); rudimentos seminais numerosos; frutos bacóides, submersos.

Descrição do genêro Victoria Lindl. (homenagem à Rainha Victoria da Inglaterra) Espécie tipo: Victoria regia Lindl.

Erva anual ou perene, de caule rizomatozo; folhas peltadas; flores flutuantes, 4 sépalas e muitas pétalas que gradualmente passam a estames laminares; ovário ínfero com numerosos carpelos unidos.

Descrição do genêro Nymphaea L. (de ninfa = habitante da água)

Espécie tipo: Nymphaea ampla (Salisb.) DC.

Erva anual ou perene; folhas sagitadas a orbiculares, profundamente partidas na base; flores grandes, emergentes, de cor branca, creme, azul, rosa ou vermelha, diurnas ou noturnas; sépalas 4; pétalas numerosas, em várias séries passando gradual ou abruptamente a estames; estames laminares, numerosos; superfície estigmática discóide, com raios estigmáticos que se prolongam em apêndices carpelares que podem ser subulados, lineares, lingulados ou claviformes.

As espécies de Nymphaea do pantanal são todas do subgênero Hydrocallis (neotropicais de floração noturna), e geralmente apresentam aroma forte de acetona, que atrai coleópteros do gênero Cyclocephala, por ocasião da antese. Geralmente as flores abrem por duas noites consecutivas. Os coleópteros ficam presos na flor durante o dia e são liberados após o primeiro e o segundo dia.

Nymphaea ampla ocorre no Mato Grosso do Sul (Bataguassu, Brasilândia e Jardim), mas provavelmente não ocorre no Pantanal, pois seria facilmente encontrada por suas flores azuis diurnas.

Chave de identificação das espécies de Nymphaeaceae do Pantanal

1. Folhas peltadas discóides quando adultas (até $2 \mathrm{~m}$ diâm.), erguidas na margem, com tabiques e acúleos na face inferior; pecíolo com acúleos ..... 8.Victoria amazonica

1. Folhas levemente peltadas, não erguidas na borda, sem tabiques e espinhos na face inferior; pecíolo sem acúleos Nymphaea

2. Plantas com folhas de base sagitada e ápice geralmente agudo

3. Folhas grandes submersas membranáceas (até $30 \mathrm{~cm}$ ); folhas pequenas flutuantes (até $6 \mathrm{~cm}$ compr.); sem esclereídeos aciculares no mesófilo; botão floral acuminado, levemente torcido no ápice, estames de cor roxa. Fig. 13-16 6. $N$. oxypetala

3. Todas as folhas flutuantes na planta adulta com esclereídeos aciculares e tricoesclereídeos no mesófilo; botão floral sem a característica anterior; estames cremes. Fig. 4-5

2. Plantas com folhas de base profundamente partidas (sagitadas) e ápice arredondado 
4. Folhas com nervuras radiais algo impressas (afundadas) na face inferior; lado inferior da folha de cor púrpura; flores com passagem abrupta de pétalas a estames; cálice estriado longitudinalmente; apêndices carpelares lingulados (algo afilados), não claviformes. Fig. 10-11 ... 5. N. lingulata

4. Folhas com nervuras salientes, radiais ou em forma de teia de aranha na face inferior; face superior com estrias longitudinais (esclereídeos aciculares no mesófilo); flores com passagem gradual de pétalas para estames

5. Folhas com nervuras em forma de teia de aranha

6. Flores com apêndices carpelares até $1 \mathrm{~cm}$ compr. e 1/5 do tamanho das sépalas; raios estigmáticos de 2,5-3cm diâm. Fig. 8-9

4. N. jamesoniana

6. Flores com apêndices carpelares cerca de $1,9 \mathrm{~cm}$ compr. e 1/3 do tamanho das sépalas; raios estigmáticos de 1-1,3cm diâm. Fig.6-7 3. N. gardneriana

5. Folhas com nervuras radiais, com protuberâncias na face superior da folha causadas pelos tricoesclereídeos do mesófilo

7. Ápice do pecíolo sem anel de pêlos; plantas com flores abortivas (tubíferas) de propagação vegetativa; apêndices carpelares levemente clavados, de cor vinho. Fig. 17-18

7. N. prolifera

7. Ápice do pecíolo geralmente circundado por um anel de pêlos; plantas sem flores abortivas; apêndices carpelares fortemente clavados, de cor vinho ou creme. Fig. 1-4

8. Folhas 1-1,35 vezes tão longas quanto largas; estames até 200 1.1. N.amazonum subsp. amazonum

8. Folhas 1,25-1,5 vezes tão longas quanto largas; estames mais de 200 1.2. N. amazonum subsp. pedersenii

Descrição das espécies

1. Nymphaea amazonum Mart. \& Zucc., Abh. Math. Phys. Cl. Königl. Bayer Akad. Wiss. 1:363. 1832. (amazonum $=$ em homenagem ao Amazonas) Fig. 1-3

Nomes populares: lagartixa (pronúncia regional largatixa); camalote-da-meia-noite, dama-da-noite, batata-dágua, pata-de-boi. $\mathrm{O}$ mesmo nome popular é aplicado às demais espécies.

Planta flutuante, fixa ao substrato; folha até 27 (32) cm compr. por 21 (26) cm larg., geralmente com manchas avermelhadas; nervuras radiais salientes; anel de pêlos no ápice do pecíolo; flores com sépalas estriadas de cor vinho; pétalas gradualmente passando a estames, em número de 110 a 323 ( 84 a 324); apêndices carpelares fortemente clavados, curvos, de cor vinho ou creme. Raios estigmáticos de 21-46 (20-47).

\subsection{N. amazonum subsp. amazonum}

Folha 1,35 vezes tão comprida quanto larga, elíptico-ovada; face superior com protuberâncias formadas pelos tricoesclereídeos; ausência de esclereídeos aciculares; flores de até 200 estames; frutos e sementes geralmente presentes. 


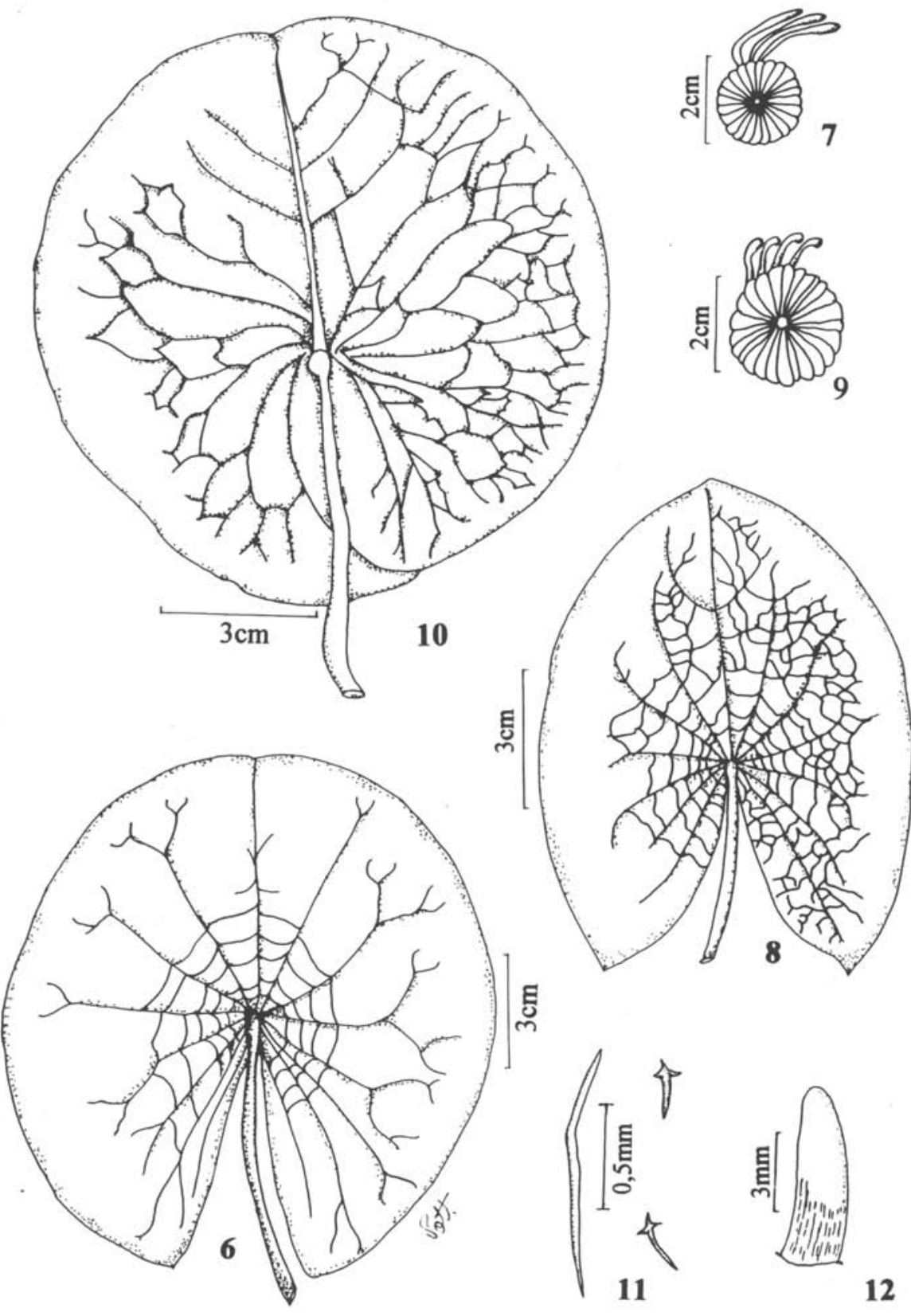

Figuras 1-3. Nymphaea amazonum: 1. folha , 1(a). anel de pêlos; 2. botão floral e corte longitudinal do botão floral; 2(a) apêndices carpelares clavados; 2(b). raios estigmáticos; 2(c). rudimentos seminais; 3 . apêndice carpelar. Figuras 4-5. Nymphaea belophylla: 4. folha; 5.(a,b,c,d,e) estames passando gradativamente de forma petalóide a estames normais. 
Floração: o ano todo.

Distribuição: América do Sul tropical e Caribe, em água parada, às vezes água levemente salobra (Wiersema 1987). Ocorre em todo o Pantanal.

Geralmente apresenta sementes, o que a diferencia da susbp. pedersenii, além do número menor de estames.

Material examinado: BRASIL. Mato Grosso do Sul: Aquidauana, faz. Fazendinha, 6/II/1991, A. Pott et al. 5855, (CPAP); Corumbá, faz. Leque, 18/VIII/1991, A. C. Cervi et al. 3326 (CPAP); faz. Nhumirim, 10/IX/1988, V. J. Pott et al. 576 (CPAP); faz. Bodoquena, 18/X/1987, V. J. Pott et al. 370 (CPAP); Baía do Tuiuiú, Rio Paraguai, 23/VII/1986, C. D. K. Cook et al. 572 (CPAP, COR, Z); Passo do Lontra, base de Pesquisa da UFMS, T. J. 18/V/1991, Gonçalves \& M. L. Melo 01 (COR); Ladário, Terminal da Branave, 12/VIII/ 1994, A. de L. Sanches et al. 43 (COR). Mato Grosso: Cáceres, Ilha de Taiamã, s/data, C. J. da Silva 212 (UFMT); Poconé, rodovia Transpantaneira km 103, 3/VIII/1981, C. J. da Silva 351 (UFMT).

1.2. N. amazonum subsp. pedersenii Wiersema. Syst. Bot. Monogr., 16:86. 1987. (pedersenii $=$ em homenagem ao botânico T. M. Pedersen)

Folha de 1,25 a 1,5 vezes tão comprida quanto larga, elíptica; face superior com protuberâncias formadas por tricoesclereídeos e às vezes com esclereídeos aciculares; flores com mais de 200 estames; apêndices carpelares 30-46; frutos e sementes geralmente ausentes.

Floração: quase o ano todo, concentrando-se nos meses de maio a outubro.

Distribuição: Argentina e Brasil subtropical (Wiersema 1987). Ocorre em todo o Pantanal.

Material examinado: BRASIL. Mato Grosso do Sul: Corumbá, faz. Leque, 4/IV/ 1995, V. J. Pott et al. 2567 (CPAP); faz. Nhumirim, 25/X/1988, V. J. Pott et al. 702 (COR); faz. Rancharia, 19/XI/1994, V. J. Pott 2481, (CPAP); BR-262, Lagoa do Jacadigo, 28/II/ 1995, V. J. Pott et al. 2538 (CPAP). Coxim, faz. Aldeia, meandro do rio Taquari, 25/II/ 1996, V. J. Pott et al. 2957 (CPAP); Ladário, rio Paraguai, 20/III/1983, C. A. Conceição 1279 (COR). Mato Grosso: Poconé, Transpantaneira km 17, 1/VII/1981, C. J. da Silva 331 (UFMT); Porto Jofre, 11/X/1989, A. Pott 5189 (CPAP); Santo Antônio de Leverger, Barra do Aricá 1/II/1996, V. J. Pott et al. 3061 (CPAP).

2. Nymphaea belophylla Trickett. Kew Bull. 26(1):29. 1971.

(belophylla $=$ folha sagitada)

Fig. 4-5

Planta flutuante, fixa ao substrato; folha de até $30 \mathrm{~cm}$ compr. e $11 \mathrm{~cm}$ larg. (Wiersema 1987) (coletas do Pantanal possuem $15 \mathrm{~cm}$ compr. por $5,5 \mathrm{~cm}$ larg.), duas a três vezes mais longa que larga, elíptica, sagitada na base e aguda no ápice; com tricoesclereídeos e esclereídeos aciculares no mesófilo; flores com pétalas gradualmente passando a estames; estames cremes; apêndices carpelares cremes de até $1,7 \mathrm{~cm}$ compr., levemente clavados.

Floração: fevereiro a abril.

Distribuição: muito incerta, talvez restrita ao Amazonas (rio Guaporé) e Pantanal, e possivelmente na Bolívia. No Pantanal ocorre em Cáceres, área de inundação do rio Paraguai, em Poconé e em Santo Antônio de Leverger. 
$N$. belophylla se parece com $N$. potamofila Wiersema (espécie do rio Amazonas) pela forma da folha, mas se distingue desta por possuir esclereídeos aciculares nas folhas e tecidos dos raios estigmáticos, que estão completamente ausentes em $N$. potamofila (Wiersema 1987).

Material examinado: BRASIL. Mato Grosso: Cáceres, BR-174, km 2,7, 19/IV/1993, V. J. Pott et al. 2049, (CPAP); Poconé, $10 \mathrm{~km}$ na estrada para Pirizal, 29/II/1996, V. J. Pott et al. 3037 (CPAP); Santo Antônio do Leverger, MT-040/361, 1/II/1996, V. J. Pott et al. 3065 (CPAP).

3. Nymphaea gardneriana Planch., Fl. Serres. Jard. Eur. 8:120. 1852.

(gardneriana $=\mathrm{em}$ homenagem ao botânico Gardner)

Fig. 6-7

Planta flutuante, fixa ao substrato; folha até $15(21,5) \mathrm{cm}$ compr. e $13(15,5) \mathrm{cm}$ larg.; subcoriácea, elíptica a suborbicular de cor avermelhada ou verde; 1 a 1,5 vezes mais longa que larga; face superior com estrias longitudinais causadas pelos esclereídeos aciculares do mesófilo; nervuras em forma de teia de aranha mais visíveis na face inferior; flores com pétalas gradualmente passando a estames; estames cremes; apêndices carpelares cremes, levemente clavados ca. de $1.9 \mathrm{~cm}$ compr. e 1/3 do tamanho das sépalas; disco de raios estigmáticos de $1-1,3 \mathrm{~cm}$ diâm.

Floração: março a dezembro.

Distribuição: América do Sul (Wiersema 1987). No Pantanal ocorre em solos arenosos ou argilosos.

$N$. jamesoniana e $N$. gardneriana diferenciam-se apenas pelo tamanho dos apêndices carpelares, sendo difícil a separação das duas espécies sem flor, porque as folhas são muito parecidas pelas nervuras em forma de teia de aranha. Apenas $N$. jamesoniana parece apresentar folhas totalmente verdes, o que não acontece em $N$. gardneriana. Ocorre freqüentemente junto com $N$. amazonum.

Material examinado: BRASIL. Mato Grosso do Sul: Aquidauana, faz. Fazendinha, baía Torta, 11/IV/1991, S. M. de Salis et al. 420 (CPAP); Corumbá, faz. Nhumirim, 5/VII/ 1990, V. J. Pott et al. 1469 (CPAP); Passo do Lontra. base de pesquisa da UFMS, 18/V/ 1991, A. L. Feitosa \& J. C. Miranda 07 (COR); faz. Santana, Paiaguás, 14/III/1985, A. Pott 1805 (CPAP). Mato Grosso: Cuiabá, mata de galeria, solo areno-argiloso alagado, 01/VI/1978, M. F. A. Macedo 740 (UFMT); Poconé, Transpantaneira km 35, 7/II/1978, R. Ehrendorfer 3103 (UFMT).

4. Nymphaea jamesoniana Planch., Fl. Serres. Jard. Eur. 8:120. 1852. (jamesoniana $=\mathrm{em}$ homenagem a W. Jameson)

Fig. 8-9

Planta flutuante, fixa ao substrato; folha até $14(23.5) \mathrm{cm}$ compr. e $11(18,5) \mathrm{cm}$ larg.; 1,18 a 1,55 vezes tão comprida quanto larga, subcoriácea, elíptica; face inferior e superior verde, com estrias longitudinais causadas pelos esclereídeos aciculares no mesófilo; nervuras em forma de teia de aranha mais visível na face inferior; flores com sépalas sem estrias longitudinais; pétalas gradualmente passando a estames; estames cremes; apêndices carpelares levemente clavados, cremes com ápices róseo-avermelhados, até $1 \mathrm{~cm}$ compr. e $1 / 5$ do tamanho das sépalas; disco de raios estigmáticos de 2,5-3 cm diâm. 


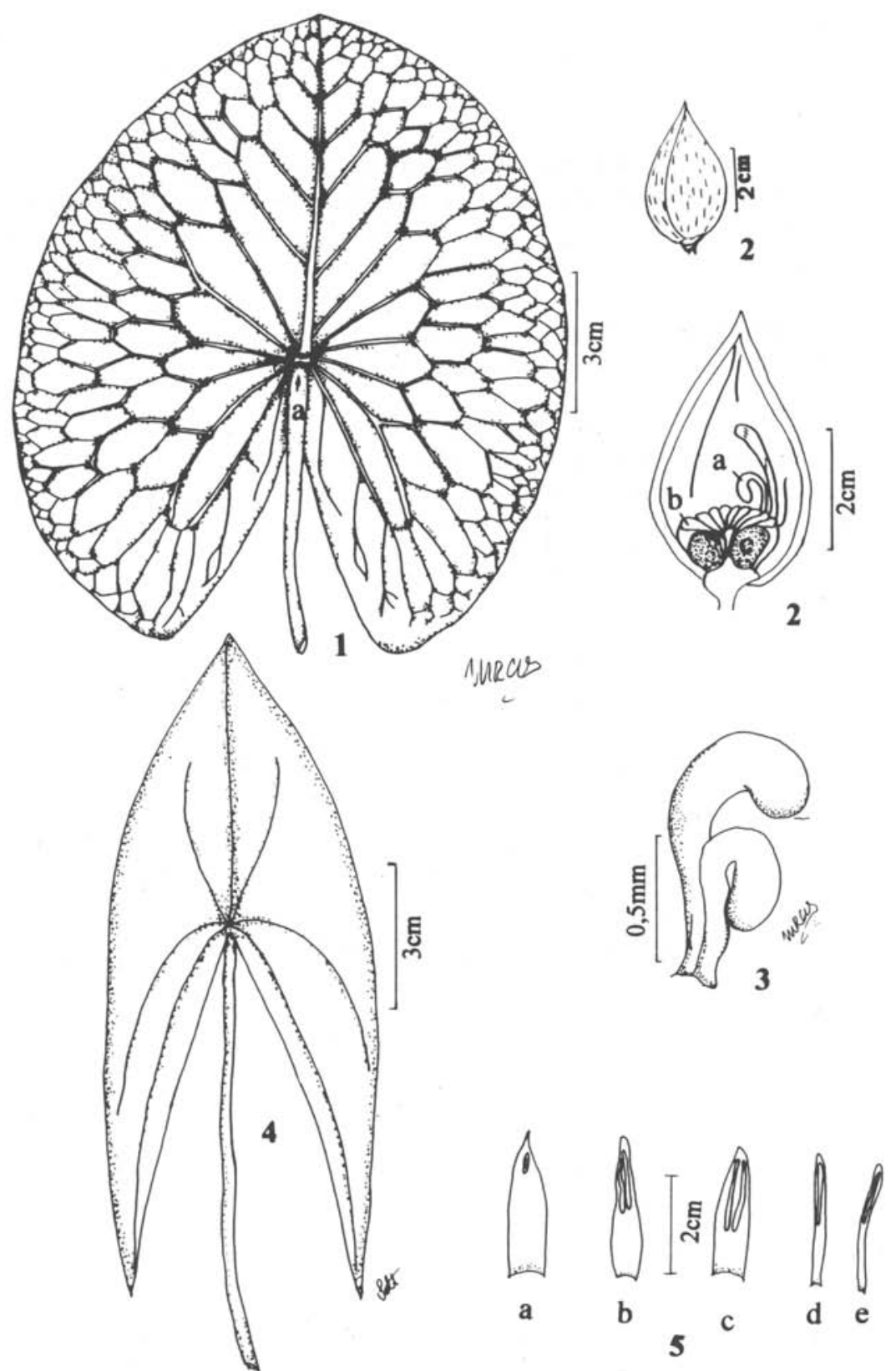

Figuras 6-7. Nymphaea gardneriana: 6. folha com nervuras em teia de aranha; 7. disco estigmático e apêndices carpelares (estaminódios). Figuras 8-9. Nymphaea jamesoniana: 8 . folha com nervuras em forma de teia de aranha; 9. disco estigmático e apêndices carpelares. Figuras 10-11. Nymphoaea lingulata: 10. folhas com nervuras impressas; 11. esclereídeo acicular e tricoesclereídeos; 12. apêndice carpelar lingulado. 
Floração: março a abril.

Distribuição: América tropical e subtropical, (Wiersema 1987). No Pantanal ocorre em solos argilosos, Nabileque e Cáceres. Encontrada $\operatorname{com} N$. oxypetala e $N$. prolifera.

Material examinado: BRASIL: Mato Grosso do Sul: Aquidauana, faz. Fazendinha, Rio Negro, 6/II/1991, V. J. Pott et al. 2331 (CPAP); Corumbá, faz. Bodoquena, 26/III/ 1989, V. J. Pott 768 (CPAP); BR-262, km 639, 19/III/1995, V. J. Pott 2564, (CPAP). Mato Grosso: Poconé, Transpantaneira, 26/III/1982, C. J. da Silva 427 (UFMT); Santo Antônio do Leverger, MT-040/361, 1/III/1996, V. J. Pott et al. 3049 (CPAP); MT-040/361, 1/III/ 1996, V. J. Pott 3051 (CPAP).

5. Nymphaea lingulata Wiersema, Brittonia, 36:215. 1984.

(lingulata $=$ forma de língua, relativo aos apêndices carpelares)

Fig. 10-11

Planta flutuante, fixa ao substrato; folha com 24 (25) cm compr. a 19 (21) cm larg.; 1 a 1.3 mais comprida que larga; ovada a suborbicular, subcoriácea; lobos da folha com protuberâncias; face superior de cor verde e quando seca com protuberância pelos tricoesclereídeos e esclereídeos aciculares; face inferior de cor púrpura e nervuras radiais algo impressas (afundadas); flores com pétalas geralmente mais longas que o cálice; transição abrupta de pétalas a estames; apêndices carpelares lingulados (algo afilados), até $14 \mathrm{~mm}$ compr., cremes a púrpuras na base.

Floração: março a dezembro.

Distribuição: Nordeste (Wiersema 1987). No Pantanal ocorre em solos arenosos, principalmente em lagoas salitradas (ligeiramente alcalinas).

$N$. lingulata distingue-se das demais espécies pela passagem abrupta de pétalas a estames, e nervuras impressas na face inferior das folhas.

Material examinado: BRASIL. Mato Grosso do Sul: Aquidauana, faz. Fazendinha, próximo ao Rio Negro, 20/XI/1995, V. J. Pott et al. 2926 (CPAP). faz. Nhumirim, 10/VIII/ 1986, C. D. K. Cooket al. 800,801 (COR, Z).

6. Nymphaea oxypetala Planch., Fl. Serres. Jard. Eur. 8:120. 1852.

(oxypetala $=$ pétalas pontudas)

Fig. 13-16

Planta submersa, fixa ao substrato; folhas pequenas (até $6 \mathrm{~cm}$ ) flutuantes, e folhas grandes submersas, sagitadas (até $30 \mathrm{~cm}$ ) membranáceas e de coloração verde arroxeada; 1,8 a 2,5 mais longas que largas; ausência de esclereídeos; flores com sépalas lanceoladas e levemente torcidas no ápice, quando em botão; pétalas gradualmente passando a estames; estames de cor roxa; apêndices carpelares de $2 \mathrm{~cm}$ compr., de cor creme, abruptamente dobrados na ponta.

Floração: março a agosto.

Distribuição: Venezuela até o Centro-Oeste do Brasil (Wiersema 1987). No Pantanal ocorre em área de inundação do rio Paraguai, Nabileque, Abobral e Poconé.

N. oxypetala distingue-se facilmente das outras espécies do Pantanal pelas folhas membranáceas submersas, sépalas e pétalas agudas e estames arroxeados.

Material examinado: BRASIL. Mato Grosso do Sul: Corumbá, faz. Bodoquena, 26/ III/1989, V. J. Pott et al. 767 (CPAP); faz. Aguaçu, 7/VI/1992, V. J. Pott 'et al. 1783 

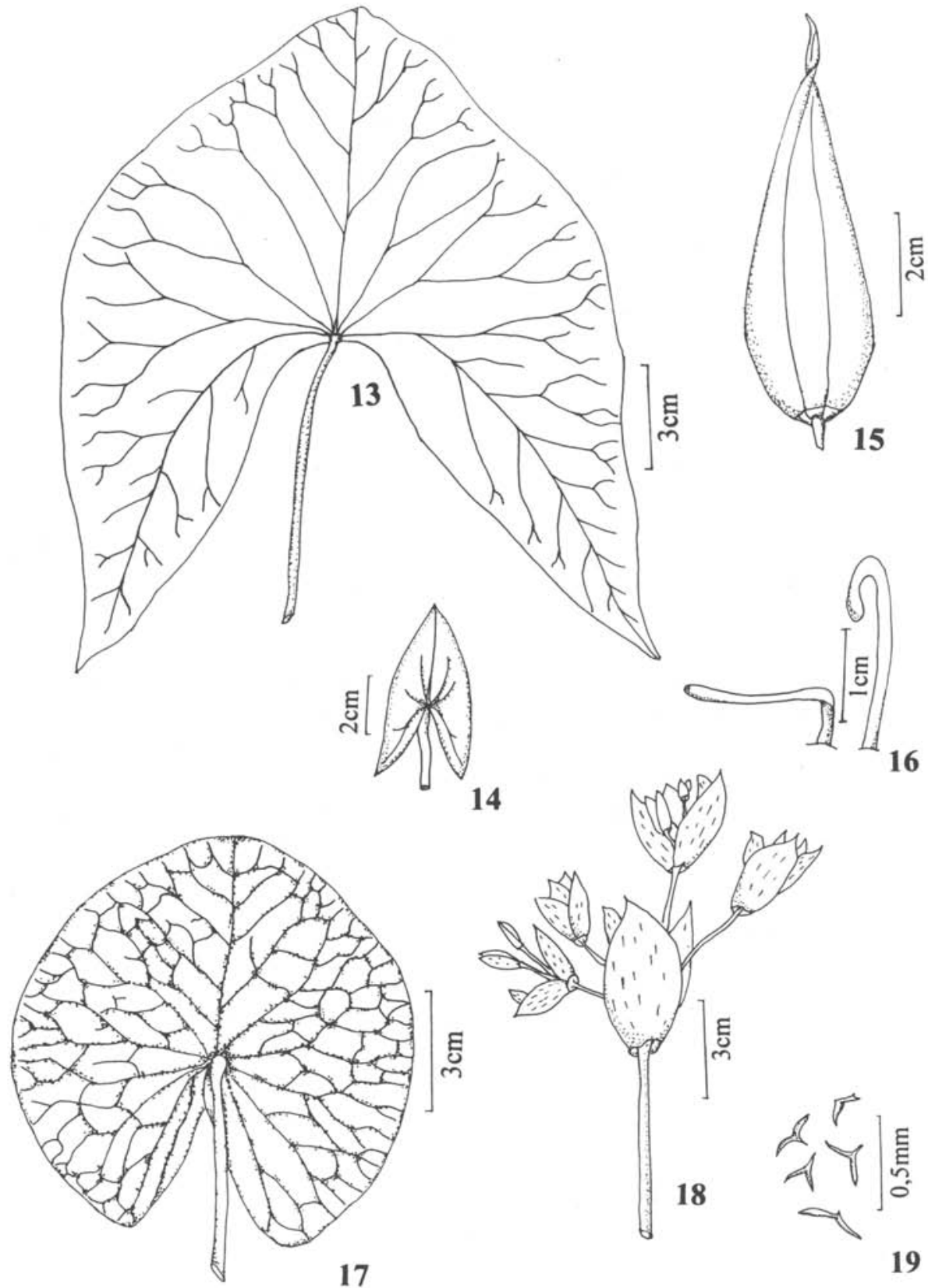

Figuras 13-16. Nymphaea oxypetala: 13. folha submersa; 14. folha flutuante; 15 . botão floral afilado; 16. apêndice carpelar. Figuras 17-18. Nymphaea prolifera: 17. folha; 18. flores tubíferas; 19. tricoesclereídeos. 
(CPAP); Rio Paraguai, Baía do Tuiuiú, 23/VII/1986, C. D. K. Cook et al. 570 (CPAP, COR, Z); faz. Leque, 4/IV/1990, V. J. Pott et al. 1334 (CPAP); próximo ao Morro do Sargento, 7/VII/1990, G. A. Damasceno Jr: 03 (COR). Mato Grosso: Poconé, Transpantaneira km 20, 23/IV/1982, C. J. da Silva 440 (UFMT); Cáceres, rio Paraguai, 6/ V/1995, Hatschbach et al. s/n. (CPAP, MBM); Santo Antônio do Leverger, MT-040/361, 1/III/1996, V. J. Pott et al. 3063 (CPAP).

7. Nymphaea prolifera Wiersema, Brittonia. 36:219. 1984.

(prolifera $=$ que produz filhos, brotos, bulbilhos vegetativos)

Fig. 17-18

Planta flutuante, fixa ao substrato; folha de 11 (22) cm compr. a 10,5 (21) cm larg.; 1 a 1,25 vezes tão comprida quanto larga; elíptica ovada a suborbicular, muitas vezes com manchas (em material seco avermelhado na face inferior); face superior com protuberâncias causadas por tricoesclereídeos apenas; ápice do pecíolo glabro; flores com sépalas de estrias longitudinais; pétalas brancas, gradualmente passando a estames, levemente maiores que o cálice, rosadas quando senescentes; apêndices carpelares levemente clavados, de cor vinho, até $1,5 \mathrm{~cm}$ compr.; flores abortivas, tubíferas (bulbilhos vegetativos) presentes, submersas.

Floração: março a jullho.

Distribuição: América do Sul e Central (Wiersema 1987). No Pantanal ocorre em campos inundados argilosos, Nabileque e Poconé.

$N$. prolifera se parece com $N$. amazonum porém não possui o anel de pêlos no ápice do pecíolo; além disto, distingue-se das outras seis por flores tubíferas.

Material examinado: BRASIL. Mato Grosso do Sul: Corumbá, baía do Jacadigo, $1 /$ XI/1990, C. R. Mendes et al. 54 (COR); BR-262, Fazenda Bodoquena, entrada para baía Bonita, 19/III/1995, V. J. Pott et al. 2563 (CPAP). Mato Grosso: Poconé, Transpantaneira km 13, 9/VI/1981, C. J. da Silva 219 (UFMT); faz. Santo Antônio, 15/IV/1993, V. J. Pott et al. 1906 (CPAP).

8. Victoria amazonica (Poepp.) Sowerby. Ann. \& Nat. Hist. Sér. II 6:310. 1850.

Sinônimo Victoria regia Lindl.

Erva anual ou perene, de pecíolo com acúleos; folha discoide de até $2 \mathrm{~m}$ diâm., com acúleos e tabiques na face inferior e bordos erguidos; flores flutuantes que abrem à noite; sépalas roxo-avermelhadas com acúleos na face exterior; apêndices carpelares em número de 14-33; sementes verde-oliva a negras, do tamanho de uma ervilha.

Floração: maio a dezembro.

Distribuição: América do Sul, nativa da Amazônia. No Pantanal ocorre no Rio Paraguai, em enseadas de água levemente corrente ou represada, em meandros abandonados quando baixa o nível da água.

Material examinado: BRASIL. Mato Grosso do Sul: Corumbá, Baía do Tamengo, 30/VI/1992, A. Pott \& A. A. Franco 6211 (CPAP); Ladário: lagoa de meandro, próx. ao terminal da Branave, 11/XII/1992, V. J. Pott 1999 (CPAP); Terminal da Branave, A. da L. Sanches et al. 44, 2/VIII/I994 (CPAP, COR). Mato Grosso: Cáceres, Rio Paraguai, ao longo da MT 174, V/1995, Hatschbach s/n., (CPAP, MBM). 


\section{Agradecimentos}

À Profa. Dra. Miramy Macedo, curadora do Herbário Central UFMT, e à Profa. Ieda Maria Bortolotto, curadora do Herbário COR-UFMS, pelo acesso ao material de Nymphaeaceae. A Admar Rodrigues, Damásio Soleto e ao técnico Antônio Arantes B. Sobrinho, pela dedicação no cultivo das plantas. A Marcos A. R. Alves, acadêmico de Biologia, por algumas ilustrações. Ao CNPq, pelo Auxílio ao projeto n5 510335/93-4.

\section{Referências bibliográficas}

Burkart. A.; Burkart, N. S. T. \& Bacigalupo, N. M. 1987. Flora Ilustrada de Entre Rios, Dicotiledoneas Arquiclamídeas. A: Salicales a Rosales (incluso Leguminosas). Buenos Aires: INTA (Colección Científica del INTA. T. 6, parte 3).

Cadavid-Garcia, E. A. 1984. O clima no Pantanal Matogrossense. Corumbá: EMBRAPA-UEPAE de Corumbá, 42 p. (Circular Técnica, 14).

Caspary, R. 1878. Nymphaeaceae. In Martius (ed.) Flora Brasiliensis. Leipzig: Monachi 4 (1, 2): 120-184.

Cook. C. D. K. 1990. Water plants of the world. The Hague: W. Junk.

Dubs. B. 1998. Prodromus Florae Matogrossensis. Küsnacht: Betrona Verlag (The Botany of Mato Grosso. Series B, n. 3).

Gessner. F. 1962. A abertura das flores de Victoria regia em relação a luz. Boletim do Museu Goeldi, Nova Série Botânica 17: 1-13.

Hoehne, F. C. 1948. Plantas aquáticas. Secretaria da Agricultura. São Paulo.

Prance. G. T. 1974. Victoria amazonica ou Victoria regia? Acta Amazonica 4(3): 5-8.

Prance, G. T. \& Anderson, A.B. 1976. Studies of the floral biology of neotropical Nymphaeaceae. Acta Amazonica 6(2): 163-170.

Prance, G. T. \& Arias, J. R. 1975. A study of the floral biology of Victoria amazonica (Poepp.) Sowerby (Nymphaeaceae). Acta Amazonica 5(2): 109-139.

Prance, G. T. \& Schaller. G. B. 1982. Preliminary study of some vegetation types of the Pantanal, Mato Grosso, Brazil. Brittonia 34: 228-251.

Trickett, R. S. 1971. A New Tropical American Waterlily. Nymphaea belophylla. Kew Bulletin 26(1): 29-31.

Wade. M. 1987. A review of the provision made for the identification of wetland macrophytes as an aid to the study and management of wetlands. Archiv für Hidrobiologie, Beiheft zur Ergebniss Limnoligie 27: 105-113.

Wiersema. J. H. 1984a. A new species of Nymphaea (Nymphaeaceae) from the Amazon Basin. Sida 10(3): 195-198.

Wiersema, J. H. 1984b. Systematics of Nymphaea subgenus Hydrocallis (Nymphaeaceae). I. Four new species from the neotropics. Brittonia 36(3): 21.3-222.

Wiersema, J. H. 1987. A monograph of Nymphaea subgenus Hydrocallis (Nymphaeaceae). The American Society of plant taxonomists. Systematic Botany Monographs 16: 46-101. 